\title{
Effects of plain packaging on decision-making and reward for nicotine cigarettes
}

REVIEW

This article was published in the following Dove Press journal:

Neuroscience and Neuroeconomics

5 May 2014

Number of times this article has been viewed

\author{
Laura E Martin ${ }^{1,2}$ \\ 'Hoglund Brain Imaging Center, \\ ${ }^{2}$ Department of Preventive Medicine \\ and Public Health, University of \\ Kansas Medical Center, Kansas City, \\ $\mathrm{KS}$, USA
}

Video abstract

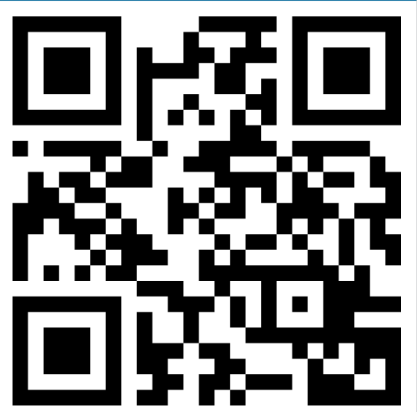

Point your SmartPhone at the code above. If you have a QR code reader the video abstract will appear. Or use: http://dvpr.es/IIYyocm
Correspondence: Laura E Martin Hoglund Brain Imaging Center, MS 1052, University of Kansas Medical Center, 390I Rainbow Boulevard, Kansas City, KS 66160, USA $\mathrm{Tel}+\mid 9135887279$

$\mathrm{Fax}+1913588907 \mid$

Email Imartin2@kumc.edu
Abstract: Cigarette smoking remains the leading preventable cause of death worldwide. Efforts to reduce smoking prevalence include changes to policies that are expected to have impacts on smoking behaviors. Plain packaging has been introduced as a method to reduce the appeal of smoking by removing such branding information as pack colors and brand logos from cigarette packages. Behavioral studies of plain packaging demonstrate reductions in the appeal of cigarette packages, changes in smoking behaviors, and expected reductions in smoking initiation. Neuroimaging studies of branding demonstrate that the neural systems of rewards and cognitive control are associated with processing brand information (eg, logos). Neuroimaging studies in smokers demonstrate that the neural systems of reward respond to images of cigarettes and are associated with reductions in cognitive control responses. The current review discusses the state of research on plain packaging in terms of a biopsychosocial model of addiction in which behavioral studies of plain packaging can identify psychological and social changes related to packaging, whereas neuroimaging studies can identify biological changes underlying the psychological and social impacts of packaging. Together, these studies show that plain packaging may reduce positive perceptions of smoking by reducing related reward responses in the brain, thus increasing the likelihood that smokers will be able to resist the urge to smoke, and perhaps quit smoking altogether.

Keywords: smoking, plain packaging, neuroimaging, branding, reward

\section{Introduction}

The World Health Organization (WHO) estimates that about 6 million people die each year from tobacco-related disease (eg, cancer, cardiovascular disease), and that approximately 600,000 of these individuals are nonsmokers who have been exposed to tobacco smoke. ${ }^{1}$ Efforts to reduce cigarette smoking range from smoking-cessation programs focused on helping an individual quit smoking to public health campaigns focused on increasing awareness of the health implications of smoking. Policy changes have also been used to reduce smoking prevalence by increasing taxation, implementing bans on advertising, and altering cigarette packaging. ${ }^{2}$ Although these efforts share the common goal of reducing smoking prevalence and preventing the initiation of smoking by nonsmokers, the focus of the current paper is on the effects of cigarette packaging on smoking perceptions and behaviors.

Despite the reluctance of tobacco companies to admit that packaging plays a key role in advertising cigarette brands, ${ }^{3}$ evidence from analyses of cigarette advertisements tell a different story. Dewe et $\mathrm{al}^{4}$ evaluated cigarette advertisements (ads) in the UK from the 1950s to 2003, when print and billboard cigarette ads were banned. The 
results suggest a decline from the 1950s to the 1990s in the use of imagery of cigarettes being smoked, as well as imagery of cigarettes not being smoked. The use of imagery of cigarette packages in ads began to increase in the 1980s. However, changes in cigarette imagery in ads have not been associated with a change in smoking prevalence. ${ }^{4}$ The lack of association between changes in cigarette imagery in ads and smoking prevalence suggests that changing the type of imagery in ads alone will not reduce smoking. On the other hand, the cigarette pack remains a prominent aspect in advertising cigarettes and is a primary vehicle to convey brand information. ${ }^{4}$ Therefore, an emerging field of research focuses on how the cigarette package impacts perceptions about smoking and what the interaction is between the cigarette package and brand information.

Branding influences consumer decisions by modifying perceptions about products and establishing emotional bonds to products. ${ }^{5}$ In the case of cigarettes, brands can portray information about the cigarette, such as taste (eg, mild), smoking experience (eg, smooth), and health risk (eg, low tar). Brands can also portray information about the smoker who smokes a certain brand of cigarette, such as sex, personality (eg, sophisticated), and social status (eg, wealthy) ${ }^{6-10}$ Moreover, branding influences both smokers and nonsmokers. For example, Gendall et $\mathrm{al}^{11}$ found that nonsmokers characterize cigarette brands with such adjectives as "sophisticated", "trendy", "professional", etc, and are more likely than smokers to associate positive attributes with familiar brands (ie, brands available for purchase). The authors suggest that this may be an artifact of smokers assigning less positive adjectives to cigarette brands, due to a smoker's negative feelings about his/her smoking (eg, guilt). However, further research is needed to understand this seemingly counterintuitive finding.

Given the power of the cigarette package to influence individuals' perceptions of cigarettes, the WHO Framework Convention on Tobacco Control's Article 11 addresses packaging and labeling of products, specifically stating that tobacco packaging should not be "misleading", and recommends plain packaging that "restricts the use of logos, brand images, and promotional information" from appearing on cigarette packages. ${ }^{1}$ The tobacco industry has been against the use of plain packaging, arguing that the effectiveness of plain packaging has not been proven, ${ }^{11}$ and that plain packaging will have little effect on purchasing behaviors. ${ }^{3}$ Tobaccocontrol activists have embraced plain packaging with the hope that it will reduce current smoking prevalence and prevent nonsmokers from becoming smokers. ${ }^{3}$ A study of tobacco- control experts from the UK, Australia, and North America reported best-guess estimates of the impact of plain packaging on smoking prevalence. Experts estimate an expected 1\% reduction in prevalence rates of smoking in adults, and a 3\% reduction in prevalence of smoking rates in children 2 years after implementing plain packaging. ${ }^{12}$ These expert opinions are in discord with reports from current smokers stating that smokers do not believe plain packaging will change their purchasing behavior, because purchases are driven by brand familiarity rather than packaging. ${ }^{13}$ However, this belief is not supported by behavioral studies of demand and purchasing behavior. ${ }^{7,14,15}$

The current review discusses behavioral studies of plain packaging and neuroimaging studies of branding, smoking, and health messaging with the goal of applying a biopsychosocial model to understand the connection between 1) the psychological aspects of plain packaging (eg, perceptions), 2) the social aspects of plain packaging (eg, social appeal), and 3) biological aspects of plain packaging (eg, associated brain activations). The paper begins with a systematic review of behavioral studies examining plain packaging. Next, the paper reviews a handful of neuroimaging studies examining brain responses associated with branding. These neuroimaging results will be compared to results of neuroimaging studies in smokers to outline how the neural systems of reward respond in individuals who currently smoke cigarettes. The paper concludes by connecting the existing behavioral research on plain packaging of cigarettes with the neuroimaging studies on branding, as well as smoking within the biopsychosocial framework. Finally, the paper concludes with a discussion of how behavioral and neuroimaging studies can perhaps inform policy decisions in an effort to reduce the prevalence of smoking and improve public health by understanding the neural underpinnings that contribute to decisions about smoking.

\section{Plain packaging of cigarettes}

Plain packaging of cigarettes has been studied from a behavioral standpoint by examining individuals' perceptions of plain-packaged cigarettes. Inclusion criteria for the literature review on plain packaging was limited to studies that met the following guidelines: 1) published (or electronic publication available) on or before January 2014; 2) experimental in nature (eg, surveys, forced choice, eye-tracking, etc); 3) assessing plain packaging in relation to branded packs; and 4) participants were from a community sample, meaning studies in which participants were tobacco-control experts were excluded. PubMed was used to identify appropriate 
literature using the search terms "plain packaging cigarettes" and "plain packaging tobacco". These search terms resulted in 119 separate articles, of which 26 (Table 1) met the inclusion criteria. The majority of excluded articles were commentary and review articles. Although many studies examining the impact of plain packaging also examined the effects of health warnings,, 911 the focus of the current review is on the effects of plain packaging. Therefore, studies that examined only the effects of health warnings were outside the scope of the current review and were excluded.

Behavioral studies of plain packaging include focus groups and opinion polls, as well as rating, forced choice decision-making, eye-tracking, willingness-to-pay, and naturalistic studies. Focus groups and opinion polls are used to introduce participants to what plain packaging is and discuss how plain packaging might change perceptions about smoking and/or the impact plain packaging may have on smoking behaviors. Rating studies are conducted via web-based surveys or in-person interviews, during which participants are presented with individual cigarette packs with varying degrees of plain packaging and asked to rate each pack on items including characteristics about the cigarettes (eg, attractiveness, taste, health risk) and/or characteristics about the smoker who would smoke cigarettes from the presented pack (eg, glamorous, trendy, low class). Similar to rating studies, forced choice decision-making tasks ask participants to assign characteristics to a cigarette pack; however, instead of rating packs individually, participants are asked to choose which cigarette pack from multiple packs best fits the presented characteristics. Eye-tracking studies assess what aspects of cigarette packs participants pay attention to most and how attention changes based on varying degrees of plain packaging. Willingness-to-pay studies assess how much participants are willing to pay for different cigarette packs. Finally, naturalistic studies examine how smoking behaviors and perceptions change when smokers are asked to smoke cigarettes from plain packages. Together, these studies are discussed in terms of how plain packaging influences perceptions, attention to warnings, demand for cigarettes, and smoking behaviors.

\section{Perceptions}

In general, plain packaging reduces the appeal of cigarettes among adolescents and adults in terms of the attractiveness or

Table I Behavioral studies of plain packing of cigarettes

\begin{tabular}{|c|c|c|c|c|c|}
\hline Study & Year & Methods & $\mathbf{n}$ & $\begin{array}{l}\text { Included } \\
\text { nonsmokers }\end{array}$ & Country \\
\hline Arora et $\mathrm{al}^{37, *}$ & 2013 & Focus group/survey & $124 / 346$ & Yes & India \\
\hline Bansal-Travers et $\mathrm{al}^{21}$ & 2011 & Forced choice & 397 & Yes & United States \\
\hline Fix et $\mathrm{al}^{38}$ & 2011 & Survey & 678 & No & United States \\
\hline Gallopel-Morvan et al ${ }^{25}$ & 2012 & Forced choice & 836 & Yes & France \\
\hline Germain et $\mathrm{al}^{6}$ & 2010 & Rate pack & $\mathrm{I}, 087$ & Yes & Australia \\
\hline Goldberg et $\mathrm{al}^{31}$ & 1999 & Recall & 401 & No & Canada \\
\hline Hammond et $\mathrm{al}^{7}$ & 2013 & Rate pack & 947 & Yes & United Kingdom \\
\hline Hammond et $\mathrm{al}^{22, * *}$ & 2009 & Forced choice & $806 / 516$ & Yes & United Kingdom \\
\hline Hammond et $\mathrm{a}^{23}$ & 2011 & Rate pack & 826 & Yes & United States \\
\hline Hammond et $\mathrm{al}^{24}$ & 2013 & Forced choice & 712 & Yes & United Kingdom \\
\hline Hoek et al ${ }^{18}$ & 2012 & Focus group & 86 & Yes & New Zealand \\
\hline Hoek et $\mathrm{al}^{40}$ & 2011 & Forced choice & 292 & No & New Zealand \\
\hline Lund and Scheffels ${ }^{8}$ & 2013 & Rate pack & $\mathrm{I}, 022$ & Yes & Norway \\
\hline Maynard et $\mathrm{al}^{33}$ & 2013 & Eye tracking & 87 & Yes & United Kingdom \\
\hline McCool et al ${ }^{9}$ & 2012 & Focus group & 80 & Yes & New Zealand \\
\hline Moodie et $\mathrm{al}^{35}$ & 2012 & Forced choice & 658 & Yes & United Kingdom \\
\hline Moodie et $\mathrm{al}^{20}$ & 2011 & Naturalistic & 140 & No & United Kingdom \\
\hline Moodie and Mackintosh ${ }^{36}$ & 2013 & Naturalistic & 301 & No & United Kingdom \\
\hline Munafò et al ${ }^{34}$ & 2011 & Eye tracker & 43 & Yes & United Kingdom \\
\hline Scheffels and Lund ${ }^{16}$ & 2013 & Forced choice/rate pack & $\mathrm{I}, 010$ & Yes & Norway \\
\hline Scheffels and Sæb $\varnothing^{17}$ & 2013 & Focus group & 69 & Yes & Norway \\
\hline Thrasher et al $^{14}$ & 2011 & Bidding & 404 & No & United States \\
\hline Wakefield et al ${ }^{15}$ & 2012 & Rate pack & $\mathrm{I}, 203$ & No & Australia \\
\hline Wakefield et al ${ }^{19}$ & 2008 & Rate pack & 813 & No & Australia \\
\hline Wakefield et al ${ }^{39}$ & 2013 & Naturalistic & 536 & No & Australia \\
\hline White et al ${ }^{10}$ & 2012 & Rate pack & 640 & Yes & Brazil \\
\hline
\end{tabular}

Notes: $*$ Included two studies - a focus group $(n=124)$ and a survey $(n=346) ; *^{*}$ included a sample of adults $(n=806)$ and adolescents $(n=516)$. 
appeal of the cigarette, ${ }^{6,7,9,10,16-20}$ and the taste of the cigarette compared to fully branded cigarettes. ${ }^{6,7,10}$ Plain packaging also alters individuals' perceptions of smokers. For instance, adolescents describe smokers of plain-packaged cigarettes as less trendy and from lower social classes than smokers of branded cigarette packages. ${ }^{6-10,20}$ Similarly, smokers of plain-packaged cigarettes are also described as having an "addictive personality", since they continue to smoke even when the appeal of smoking has been removed along with the branding. ${ }^{9}$ Therefore, changes in perceptions about the smokers of plain-packaged cigarettes appear to increase social stigma.

Plain packaging has also been associated with perceptions that plain-packaged cigarettes have different tar levels and health risks compared to branded packs, indicating that branding not only increases the appeal of smoking but also influences perceptions of health risks..$^{6,7,9,10}$ In general, plain-packaged cigarettes are perceived as having higher tar levels and/or increased health risks. ${ }^{7,9,21-23}$ However, the color of the plain package can influence the perception of health risks among smokers. ${ }^{22}$ Specifically, plain packaging in white boxes is perceived as having fewer health risks than fully branded packaging, whereas plain packaging in brown boxes is perceived as having greater health risks. $^{22}$ This is consistent with the tobacco industry's use of white backgrounds on fully branded cigarette packages, presumably due to the association of the color white with connotations of cleanliness and healthiness. ${ }^{22}$ In addition, the shape of the plain-packaged box can also influence perceptions of risk. For example, "lipstick" boxes are perceived as having lower health risks, even when packaged without branding. ${ }^{23}$

Many studies examining plain packaging include both smokers and nonsmokers, and show differences in the influence of plain packaging on perceptions. For example, smokers rate cigarettes as less harmful than nonsmokers. ${ }^{24}$ Motivation to quit smoking also influences smokers' choices, in that smokers who are more motivated to quit are more likely to choose plain-packaged cigarettes, ${ }^{25}$ thus supporting the perception that plain packaging will help smokers quit smoking. Some studies show that smokers appear to assign more positive characteristics to branded and plain-packaged cigarettes compared to nonsmokers. ${ }^{6}$ This is inconsistent with studies that focus only on branded cigarettes, and indicates that nonsmokers compared to smokers assign more positive characteristics to familiar brands than unfamiliar brands. ${ }^{11}$ The major difference between these studies is the inclusion of plain-packaged cigarettes. How these differences in perceptions may influence smoking initiation among nonsmokers will be discussed in more detail.

Similar to how smoking status can change perceptions about cigarettes, perceptions also vary by sex..$^{7,10,20}$ This is an important aspect to discuss in terms of cigarette packaging, since advertising of cigarettes has targeted women in the past by focusing on ideals of thinness, sex appeal, and feelings of belonging. ${ }^{26,27}$ Studies examining the effects of plain packaging among women point out that branding for women is associated with lighter colors and fonts that convey femininity. Studies in female smokers are consistent with other studies of plain packaging showing reductions in positive attributes associated with smoking. ${ }^{7,10,20}$ Moreover, Lund and Scheffels ${ }^{8}$ directly compared perceptions of cigarette packaging in male and female adolescents, and found that female adolescents associated fewer positive traits with plain packs compared to fully branded packs, whereas male adolescents showed little difference between plain and standard packs. Overall, these results indicate that women may be more sensitive than men to branding information displayed on packs.

Perceptions associated with plain packaging also vary by race and ethnicity. Specifically, Hammond et $\mathrm{al}^{7}$ found that nonwhite smokers rate branded packaging as better tasting and more appealing than white smokers. Racial differences also exist in perception of the health risks associated with cigarettes. Hammond et $\mathrm{al}^{7}$ found that nonwhite smokers rated branded packaging as healthier. Similarly, White et al ${ }^{10}$ found that nonwhite adolescents rated branded packs as less harmful. Given the disproportionately greater tobacco-related disease burden among nonwhite smokers ${ }^{28-30}$ and the seemingly increased impact of branding on the perception of cigarettes, these results indicate that plain packaging could have an impact on reducing health disparities by decoupling positive rewards associated with branding from cigarettes.

\section{Attention to health warnings}

In addition to changing perceptions about smoking, plain packaging also changes what aspects of the package attract the most attention. Examining the effects of plain packaging on attention is not a new line of research. In fact, studies in the 1990s examined the impact of plain packaging. ${ }^{31,32}$ The most consistent finding in terms of attention is that plain packaging increases attention to health warnings. This is achieved by increasing recall of health messages. ${ }^{31,32}$ Similarly, eyetracking studies demonstrate that plain packaging increases the number of eye movements toward warning labels. ${ }^{33,34}$

As with perceptions associated with plain packaging, attention to warning labels also appears to be related to 
smoking status. Specifically, occasional and weekly smokers pay equal attention to branding and health-warning information on branded cigarette packs, but selectively pay more attention to health warnings on plain packs. ${ }^{33,34}$ Furthermore, never-smokers typically pay more attention to health warnings regardless of pack type, and spend more time looking at branded packs compared to plain packs. ${ }^{33,34}$ Daily smokers, on the other hand, show no differences in attention for branding compared to health warnings on branded and plain packs. ${ }^{33,34}$

\section{Demand for plain-packaged cigarettes}

Another approach to examining the impact of plain packaging is to assess participants' desire to obtain cigarettes from plain compared to branded cigarette packs (ie, demand). Thrasher et $\mathrm{al}^{14}$ found that plain packaging reduces demand for cigarettes in terms of reducing the price smokers are willing to pay to purchase cigarettes in plain packages. Moreover, plain packaging appears to reduce demand to a greater degree than increasing the size of graphic health warnings. ${ }^{14,15}$ The effect of plain packaging on cigarette demand could be due to perceptions that the combination of branding and graphic health warnings sends competing messages about smoking and is "confusing", because the branding and health warnings convey opposite messages. $^{9}$

Similarly, in forced choice decision-making studies where participants are offered a pack of cigarettes as part of the study, smokers and nonsmokers are less likely to say yes to receiving a pack of plain-packaged cigarettes compared to branded packages. ${ }^{7}$ Although nonsmokers will accept packs of cigarettes, smokers are more likely to accept a pack than non-smokers. ${ }^{10}$ Furthermore, nonsmokers tend to base their decisions on the pack with the lower perceived health risk, whereas smokers equally choose higher- and lower-risk packs. ${ }^{21}$ This suggests that plain packages that increase perceptions of health risk may also impact initiation of smoking.

\section{Change in smoking behaviors}

As described earlier, plain packaging can alter perceptions about cigarette and smoker characteristics; however, the question remains as to whether or not these changes in perception lead to changes in behavior. Recent studies have begun to look at smoking behaviors associated with plain packaging in real-world settings. Studies examining the impact of plain packaging on smoking behaviors have asked participants to smoke cigarettes from plain packaging for 1-2 weeks compared to 1-2 weeks of smoking their usual fully branded packs. ${ }^{35,36}$ The results across two separate studies showed decreases in positive perceptions of the cigarettes and increases in negative feelings (eg, embarrassment) when smoking plain-packaged cigarettes. ${ }^{35,36}$ In addition, smokers reported engaging in more avoidant behaviors around smoking, and even reducing the number of cigarettes smoked. ${ }^{35,36}$ These studies provide a real-world example of how plain packaging can help with smoking cessation and smoking reduction. Furthermore, these studies also align with findings that smokers support policies on plain packaging due to beliefs that plain packaging may help them change their smoking behaviors and/or quit smoking. . $5,37,38$

Moreover, since Australia became the first country to implement a policy of plain packaging in 2012, ${ }^{39}$ studies have been able assess the impact of plain packaging on smoking perceptions and behaviors away from an experimental setting. Wakefield et $\mathrm{al}^{39}$ performed a cross-sectional study during the first months of implementation of plain packaging in Australia in late 2012. The results were consistent with behavioral studies showing that smokers of plain-packaged cigarettes perceive their cigarettes to be lower in quality, and in turn experienced less satisfaction from smoking the plain-packaged cigarettes. Australian smokers also reported thinking about quitting and prioritizing quitting more than they did while smoking fully branded cigarettes. ${ }^{39}$ Overall, Australian smokers of plain-packaged cigarettes are more likely to support the use of plain packaging compared to Australian smokers who are still smoking cigarettes from branded packages. ${ }^{39}$

\section{Initiation of smoking}

Although no data are currently available on the impact of plain packaging on smoking initiation, behavioral studies have asked participants to assess whether or not they think plain packaging would deter nonsmokers from smoking. These studies suggested that both smokers and nonsmokers thought plain packaging would prevent nonsmokers from initiating smoking. ${ }^{24,25,35}$ Expected reductions in initiation of smoking are supported by data indicating that plain packaging reduces the appeal of smoking to youth. ${ }^{21,25,35,37,40}$

\section{Limitations of plain-packaging research}

Despite evidence supporting plain packaging, there are limitations in the current literature. For instance, inconsistencies exist in perceptions of health risks associated with cigarettes from plain packages. However, these inconsistencies appear to be related to pack color and pack design, in that lighter colors and packs that move away from the standard pack design are associated with fewer health risks. Therefore, 
findings between different types of plain packaging complicate the existing literature by introducing seemingly contradictory results and highlighting the need to pay close attention to pack design, even when branding information is removed. However, studies that include multiple versions of plain-packaged cigarettes (eg, Hammond et $\mathrm{al}^{22}$ ) strengthen the current research by indicating that removing branding alone may not be enough to reduce smoking prevalence and initiation.

Moreover, studies assessing perceptions of plain packaging have included both smokers and nonsmokers, which could introduce bias for negative connotations of smoking among individuals who have struggled with smoking for years and are motivated to quit smoking. On the other hand, the inclusion of smokers and nonsmokers could introduce bias for neutral-to-positive connotations of smoking among individuals who are not motivated to quit or ambivalent about their smoking.

Furthermore, the majority of research to date has focused on experimental settings and focus groups to evaluate perceptions of plain packaging and expected purchasing behavior; therefore, further studies will need to be done in real-world settings. Computer-based tasks, such as surveys and forced choice decision-making tasks, remove the three-dimensionality of the cigarette pack and take away an individual's ability to interact with the pack as they might outside the lab. Some studies have attempted to minimize this limitation by displaying the pack in multiple views or conducting naturalistic studies. Naturalistic studies remove this limitation completely by having participants smoke cigarettes out of a plain pack for 1-2 weeks, and results have been consistent with other lab- or survey-based studies.

Perhaps the biggest limitation of plain-packaging studies to date is that these studies include both plain and branded packs, thus imposing comparisons of the plain to the branded pack. Even if participants rate the packs independently of each other, there remains an inherent comparison to branded packs that are readily available outside the study. This is a limitation that can only be removed by removing branded packs from the study environment, as well as the market place. Therefore, until we can compare smoking prevalence in such countries as Australia between generations that have and have not been exposed to branded packs, we cannot fully remove the influence of the exposure of branded packs on perceptions of plain packs.

The first step in this direction has been examining the first months following the implementation of plain packag- ing in Australia, which replicated behavioral studies showing decreases in positive perceptions of cigarettes from plain packaging, as well as increases in thoughts about quitting. Moreover, Australia has seen an increase in the number of Quitline phone calls since the implementation of plain packaging, suggesting that plain packaging is increasing quit attempts. ${ }^{41}$ In addition, an observational study of smoking in public places and smokers displaying their cigarette packs on tables in public shows a decline in exposure to smoking and smoking-related cues in public. ${ }^{42}$

\section{Summary}

Despite these limitations, strengths of the behavioral research on plain packaging of cigarettes include the overall consistency across study designs, in that focus groups, opinion polls, forced choice decision-making studies, and naturalistic studies consistently demonstrate that plain packaging reduces the appeal of cigarettes. Moreover, these perceptions are carrying over to changes in smoking behaviors, quit attempts, and public smoking in Australia following the 2012 implementation of plain-packaged cigarettes. ${ }^{39,41,42}$

In terms of a biopsychosocial model, plain packaging appears to impact the psychological and social components of smoking by altering perceptions of not only the cigarette but also the smoker. Moreover, these alterations in perceptions appear to contribute to changes in smoking behaviors. In addition, a biological interaction between plain packaging and perceptions is emerging, given the sex and racial differences in perceptions about cigarettes from plain packages. Further research is needed to see if differences in plain packaging are related to hormonal or genetic variations. Little has been done to assess the biological aspects of plain packaging from a psychophysiological or neurological perspective to understand the neural mechanisms underlying smokers' perceptions and behaviors associated with plain packaging of cigarettes. To date, no published neuroimaging studies have looked specifically at the effect of plain packaging of cigarettes; however, the growing fields of neuroeconomics and neuromarketing can offer insights about the association between branding and brain activations.

\section{Neuroimaging studies of branding}

Neuroimaging studies of advertising include studies examining differences in brain responses to types of brands (eg, luxury versus nonluxury) or types of products (eg, food versus nonfood). Overall, these studies indicate that rewardprocessing regions, including the ventral striatum, inferior frontal gyrus, and ventromedial prefrontal cortex (VMPFC) 
are involved in processing rewarding information about a brand. ${ }^{5,43}$ Self-referencing regions and cognitive control regions such as the dorsolateral PFC (DLPFC) and the anterior cingulate cortex (ACC) are involved in evaluating the relationship of a product to an individual and determining what actions to take in response to the branding information (eg, buy the product). ${ }^{5,43}$

Brain regions activated by branding information vary based on the task. For instance, Schaefer et $\mathrm{al}^{44}$ show that the medial PFC (MPFC) selectively responds to brand familiarity. ${ }^{44}$ Cultural or social status associated with a brand is also differentiated by reward-related brain activity, as Schaefer and Rotte ${ }^{45}$ demonstrated in a study finding activation in cognitive control regions (ACC) to value-car brands and activation in reward regions (MPFC) to luxury brands. ${ }^{45}$ Furthermore, viewing commercials is associated with activations in reward-processing regions and changes based on how pleasurable the commercials are perceived to be. ${ }^{46}$ Activation in response to brand also varies based on mode of presentation. For example, increases in activation in the VMPFC have been found when participants evaluate the taste of a soft drink. ${ }^{43}$ However, when participants are also presented with a visual cue of the soft drink logo, the DLPFC is activated, which is associated with self-referential behavior and cognitive control. ${ }^{43}$

Although the majority of neuroimaging studies examining branding have focused on adult consumers, similar results have been found in children. In a study examining food logos, healthy-weight children showed increases in responses to food logos in reward-processing regions. ${ }^{47,48}$ In addition, obese children showed reductions in activation in such cognitive control regions as the DLPFC when viewing food logos, indicating that obese children may be more susceptible to branding of food than healthy-weight children. ${ }^{48}$

\section{Limitations}

Similar to other lab-based studies, neuroimaging studies are limited in the type of stimuli that can be presented. Specifically, functional magnetic resonance imaging (fMRI) studies require that a subject is lying down in the scanner and holding very still. Moreover, the majority of neuroimaging studies examining brain activations while participants are exposed to brands have not examined how these brain activations relate to real-world purchasing behaviors. Finally, in the absence of neuroimaging studies on plain packaging, little is known about the translation of neuroimaging studies of branding from one commodity to another (eg, food to smoking).

\section{Summary}

Despite these limitations, neuroimaging studies examining brain responses associated with branding find activation increases in the neural systems of reward and cognitive control. ${ }^{5,43-45,47,48}$ Neuroimaging studies of branding indicate that the neural systems of reward and cognitive control are involved in processing the reward value of the branding, both in terms of the absolute reward value (VMPFC), and the value of the reward to an individual (DLPFC, ACC). These regions activate differently based on the mode of presentation, as well as the individual, social, and cultural value of the brand.

These neuroimaging results complement behavioral studies of plain packaging by emphasizing the intricacy of branding. Behavioral studies of plain packaging show that individuals' perceptions of plain compared to branded packs are associated with changes in perceptions about the characteristics of the cigarette, as well as the social appeal of smoking (eg, how others will view a smoker of plain cigarettes). Not surprisingly, neuromarketing studies suggest that these differences in perception may be guided by differences in brain activity in regions related to the evaluation of reward values. Therefore, plain packaging of cigarettes would be expected to result in decreased activation in such regions as the VMPFC when participants view cigarettes from plain compared to fully branded packs. In terms of the biopsychosocial model, neuroimaging studies offer a tool to assess the biological changes (eg, percentage signal change from baseline) associated with different stimuli. In the case of branding, the biological changes are indexed by brain activations when exposed to one brand condition compared to another brand condition.

\section{Neuroimaging studies of smoking}

In addition to neuroimaging research on branding, neuroimaging studies examining smokers can also provide insight into how plain packaging of cigarettes may impact brain activity. The majority of neuroimaging studies in smokers focus on brain responses while viewing smoking cues; however, there has been recent research examining responses to health messaging among smokers.

\section{Cue reactivity}

Smoking cues include images of cigarettes, people smoking, or behaviors leading up to smoking that can trigger cravings and ultimately lead to smoking. Given that smoking cues include packages of cigarettes, these studies can provide insight into the effect of branded cigarettes on the neural 
systems of reward and cognitive control. Smoking cues are associated with increases in brain responses among smokers, but not nonsmokers. ${ }^{49}$ Many studies show increased activations in reward processing and cognitive control regions, including the ventral striatum, MPFC, orbitofrontal cortex (OFC), and ACC. ${ }^{50-53}$ In a recent meta-analysis of fMRI cuereactivity studies, Engelmann et $\mathrm{l}^{54}$ reported that smoking cues reliably activate regions related to reward processing, memory, cognitive control, and interoceptive awareness.

As with neuroimaging studies on branding, many factors influence brain responses to smoking cues. Brain regions that respond to smoking cues respond differently based on smokers' expectations to smoke during the experiment, motivation to quit smoking, ${ }^{55,56}$ self-report levels of nicotine dependence, ${ }^{57-59}$ and smoking ambivalence. ${ }^{60}$ For example, among smokers who are not interested in quitting smoking, areas of the PFC associated with goal-directed behaviors and decision-making show increased functional connectivity to reward such evaluation areas as the OFC when smokers are expecting to smoke immediately following the neuroimaging scan. ${ }^{56}$ Moreover, smokers who slip (smoked any cigarettes during nicotine-replacement treatment) following a quit attempt show increased activation in areas associated with emotion, motor planning, and interoceptive awareness, and decreased functional connectivity between these areas and cognitive control areas prior to a quit attempt. ${ }^{61}$ Self-report measures of dependence are positively correlated with brain responses to smoking cues in reward-evaluation areas, but negatively correlated with brain responses in memory and attention areas. ${ }^{58}$ In addition, neuroimaging studies in smokers have also examined the effects of smoking-cessation pharmacotherapy (eg, bupropion, varenicline) compared to placebo ${ }^{62,63}$ or compared to untreated smokers. ${ }^{64}$ Specifically, pharmacotherapy for smoking cessation is associated with reductions in brain responses in regions related to smoking reward. ${ }^{62-64}$

\section{Health messaging}

In addition to studies examining brain responses associated with cue reactivity, studies have also examined the brain responses associated with health messaging by having smokers view public health messages about smoking while in the MRI machine. ${ }^{65}$ Results demonstrate that activation in the dorsal MPFC is associated with reductions in smoking behaviors. These results are similar to previous studies demonstrating that activity in the MPFC while viewing persuasive messages is associated with behavioral changes. ${ }^{66,67}$ Moreover, in a recent electrophysiological study, the presentation of highly emotional graphic warning labels immediately before a smoking cue was associated with a reduction in the $\mathrm{P} 300$ event-related potential, an index of incentive value. $^{68}$

\section{Limitations}

As with limitations of neuroimaging studies of branding, neuroimaging studies in smokers are limited by the testing environment. As described earlier, many factors influence brain responses among smokers, including such psychological factors as participants' motivation to smoke and such physical factors as withdrawal, which is associated with time since last cigarette and dependence levels. Although neuroimaging studies of cue reactivity offer insight into how a smoker responds to images of smoking-related cues, these responses are influenced by prolonged exposure to these cues while smoking, ranging from merely experimenting with smoking to smoking more than a pack a day for $30+$ years, depending on how frequently and how long an individual has smoked. Moreover, the majority of cue-reactivity studies focus on moderate-to-heavy smokers (eg, smoke more than ten cigarettes per day). Therefore, these studies do not offer much insight into smoking initiation, or exposure to plain-packaged cigarettes that are unfamiliar to the majority of smokers.

\section{Summary}

Despite these limitations, neuroimaging studies of smoking examining brain responses related to processing smoking cues, which often include cigarette packages, find increases in brain responses in reward-processing brain regions. ${ }^{50-53}$ Neuroimaging studies of cue reactivity demonstrate that these activations vary based on the current state of the smoker (eg, motivated to quit, time since last cigarette, taking pharmacotherapy for smoking cessation). However, neuroimaging studies have not examined brain responses associated with processing plain-packaged cigarettes.

Given the fact that a cigarette pack can serve as a smoking cue, we may expect branded packs to activate the same regions seen in other cue-reactivity studies, and can hypothesize that plain packs would activate these regions to a lesser degree. However, reduced activation to plain packages could result from less familiarity and less exposure (eg, cue-response conditioning) to plain packages. Future behavioral and neuroimaging studies in countries that have implemented plain packaging are needed to understand fully how plain packaging influences craving and/or cue-reactivity responses. 
On the other hand, brain activations associated with plain packaging of cigarettes could also influence regions associated with health messaging. Given that plain packaging has been shown to increase attention to warning labels and may lead to quit attempts, future neuroimaging studies could also examine whether or not there is an association between brain activations when viewing plain-packaged cigarettes and successful quit attempts. One goal of this line of research would be to identify individuals who may be more or less responsive to plain packaging.

Like neuroimaging studies of branding, neuroimaging studies of cue reactivity and health messaging in smokers contribute to the biopsychosocial model by providing a biological measure that can be assessed under different psychological states. Future research specifically examining the brain responses associated with plain packaging of cigarettes is needed to understand how these biological, psychological, and social aspects of plain packaging interact and contribute to changes in smoking behaviors and prevent the initiation of smoking among nonsmokers.

\section{Discussion and conclusion}

Overall, plain packaging reduces positive perceptions associated with cigarettes and smokers. Plain packaging alters perceptions of negative health risks. Furthermore, neuroimaging studies of branding show activation in brain regions that evaluate reward value associated with branding information, and these same regions are activated among smokers when viewing smoking cues. Neuroimaging studies of branding and cue reactivity also show activation of cognitive control regions, presumably when an individual is trying to control his/her behavior in response to branding information or smoking cues. This pattern of response is epitomized in the case of health messaging, where greater activation in dorsal regions of the MPFC is associated with behavior change in the form of smoking reduction.

Policies related to plain packaging could reduce smoking prevalence by acting at the individual, social, and behavioral level to change smoking behaviors. Therefore, policy changes could act as the antecedent to a biopsychosocial behavioral change model, ${ }^{69}$ such as the biobehavioral model of nicotine addiction and tobacco-related cancers, ${ }^{70}$ which explains smoking as resulting from multifaceted relationships between social, psychological, and biological factors. In this model, policy change could be related to social factors (eg, perceptions about smokers) and psychological factors (eg, feelings about smoking) that are associated with smoking behaviors. Policy changes could also directly influence smoking behaviors by reducing access to cigarettes. In the case of plain packaging, the biggest influence is most likely on the social and psychological factors associated with smoking due to the shifts in perception about the cigarette itself, as well as social perceptions about the type of person who would smoke cigarettes from plain packaging.

In addition, policy changes could be incorporated into neurobiological models of addiction. For instance, Volkow et $\mathrm{al}^{71}$ proposed a model that describes the connectivity between reward areas and other brain regions associated with drug-taking and drug-seeking behaviors. This model emphasizes four neural circuits: reward (limbic regions), memory (amygdala and hippocampus), drive (OFC), and control (PFC and ACC).$^{72}$ Increased sensitivity to the anticipation of drug reward (eg, smoking) is accompanied by decreased sensitivity to natural rewards (eg, food, sex). The anticipation of drug reward is enhanced by memories of previous drug experiences, and overrides the control responses as motivational drive takes over in the form of drug-seeking behaviors. Policy changes in cigarette packaging could indirectly act on this model by reducing branding information and therefore reducing the number of smoking cues in the environment, while at the same time reducing activations in the reward circuits.

Together, these behavioral and neurobiological models support a hypothesis that plain packaging could contribute not only to changes in perceptions about smoking but also changes in the neural systems involved in evaluating the rewarding value of cigarettes. Specifically, plain-packaged compared to branded-packaged cigarettes could reduce activation in reward regions and increase activation in cognitive control regions. These hypothesized changes are based on the behavioral literature of plain packaging and the neuroimaging literature described earlier. Although neuroimaging studies assessing brain responses to smoking cues show results reminiscent of neuroimaging studies in branding, further research is needed to see how smokers' perceptions of plain-packaged cigarettes are associated with brain responses in the neural systems of reward and cognitive control.

Behavioral and neuroimaging studies show that plain packaging may reduce positive perceptions of smoking by reducing related reward responses in the brain, thus increasing the likelihood that smokers will be able to resist the urge to smoke. Given the relationship between smoking cues, branding and cigarette packaging, future research should focus on relationships between policy and behavioral and neurobiological changes associated with reducing smoking prevalence and improving overall public health. This line of 
research would add a neurobiological argument in support of plain packaging that could influence policy changes by demonstrating the relationships between biological, psychological, and social factors that connect plain packaging of cigarettes to changes in smoking behavior and the initiation of smoking.

\section{Disclosure}

The author reports no conflicts of interest in this work.

\section{References}

1. WHO. WHO Report on the Global Tobacco Epidemic, 2011: Warning about the Dangers of Tobacco. Geneva: WHO; 2011.

2. Currow DC, Dessaix A. Plain packaging for tobacco products. $B M J$. 2011;343:d5693.

3. Freeman B, Chapman S, Rimmer M. The case for the plain packaging of tobacco products. Addiction. 2008;103(4):580-590.

4. Dewe M, Ogden J, Coyle A. The cigarette box as an advertising vehicle in the United Kingdom: a case for plain packaging. J Health Psychol. Epub October 22, 2013.

5. Schaefer M. Neuroeconomics: in search of the neural representation of brands. Prog Brain Res. 2009;178:241-252.

6. Germain D, Wakefield MA, Durkin SJ. Adolescents' perceptions of cigarette brand image: does plain packaging make a difference? J Adolesc Health. 2010;46(4):385-392.

7. Hammond D, Daniel S, White CM. The effect of cigarette branding and plain packaging on female youth in the United Kingdom. J Adolesc Health. 2013;52(2):151-157.

8. Lund I, Scheffels J. Young smokers and non-smokers perceptions of typical users of plain vs branded cigarette packs: a between-subjects experimental survey. BMC Public Health. 2013;13(1):1005.

9. McCool J, Webb L, Cameron LD, Hoek J. Graphic warning labels on plain cigarette packs: will they make a difference to adolescents? Soc Sci Med. 2012;74(8):1269-1273.

10. White CM, Hammond D, Thrasher JF, Fong GT. The potential impact of plain packaging of cigarette products among Brazilian young women: an experimental study. BMC Public Health. 2012;12:737.

11. Gendall P, Hoek J, Edwards R, McCool J. A cross-sectional analysis of how young adults perceive tobacco brands: implications for FCTC signatories. BMC Public Health. 2012;12:796.

12. Pechey R, Spiegelhalter D, Marteau TM. Impact of plain packaging of tobacco products on smoking in adults and children: an elicitation of international experts' estimates. BMC Public Health. 2013;13:18.

13. Uppal N, Shahab L, Britton J, Ratschen E. The forgotten smoker: a qualitative study of attitudes towards smoking, quitting, and tobacco control policies among continuing smokers. BMC Public Health. 2013;13:432.

14. Thrasher JF, Rousu MC, Hammond D, Navarro A, Corrigan JR. Estimating the impact of pictorial health warnings and "plain" cigarette packaging: evidence from experimental auctions among adult smokers in the United States. Health Policy. 2011;102(1):41-48.

15. Wakefield M, Germain D, Durkin S, Hammond D, Goldberg M, Borland R. Do larger pictorial health warnings diminish the need for plain packaging of cigarettes? Addiction. 2012;107(6):1159-1167.

16. Scheffels J, Lund I. The impact of cigarette branding and plain packaging on perceptions of product appeal and risk among young adults in Norway: a between-subjects experimental survey. BMJ Open. 2013;3(12):e003732.

17. Scheffels J, Sæbø G. Perceptions of plain and branded cigarette packaging among Norwegian youth and adults: a focus group study. Nicotine Tob Res. 2013;15(2):450-456.

18. Hoek J, Gendall P, Gifford H, et al. Tobacco branding, plain packaging, pictorial warnings, and symbolic consumption. Qual Health Res. 2012;22(5):630-639.
19. Wakefield MA, Germain D, Durkin SJ. How does increasingly plainer cigarette packaging influence adult smokers' perceptions about brand image? An experimental study. Tob Control. 2008;17(6):416-421.

20. Moodie C, Ford A, Mackintosh AM, Hastings G. Young people's perceptions of cigarette packaging and plain packaging: an online survey. Nicotine Tob Res. 2012;14(1):98-105.

21. Bansal-Travers M, Hammond D, Smith P, Cummings KM. The impact of cigarette pack design, descriptors, and warning labels on risk perception in the US. Am J Prev Med. 2011;40(6):674-682.

22. Hammond D, Dockrell M, Arnott D, Lee A, McNeill A. Cigarette pack design and perceptions of risk among UK adults and youth. Eur J Public Health. 2009;19(6):631-637.

23. Hammond D, Doxey J, Daniel S, Bansal-Travers M. Impact of female-oriented cigarette packaging in the United States. Nicotine Tob Res. 2011;13(7):579-588.

24. Hammond D, White C, Anderson W, Arnott D, Dockrell M. The perceptions of UK youth of branded and standardized, 'plain' cigarette packaging. Eur J Public Health. Epub October 8, 2013.

25. Gallopel-Morvan K, Moodie C, Hammond D, Eker F, Beguinot E, Martinet Y. Consumer perceptions of cigarette pack design in France: a comparison of regular, limited edition and plain packaging. Tob Control. 2012;21(5):502-506

26. Anderson SJ, Glantz SA, Ling PM. Emotions for sale: cigarette advertising and women's psychosocial needs. Tob Control. 2005;14(2): 127-135.

27. Carpenter CM, Wayne GF, Connolly GN. Designing cigarettes for women: new findings from the tobacco industry documents. Addiction. 2005;100(6):837-851.

28. American Cancer Society. Cancer Facts and Figures 2010. Atlanta: ACS; 2010.

29. Haiman CA, Stram DO, Wilkens LR, et al. Ethnic and racial differences in the smoking-related risk of lung cancer. $N$ Engl J Med. 2006;354(4):333-342.

30. Centers for Disease Control and Prevention (CDC). Cigarette smoking among adults and trends in smoking cessation - United States, 2008. MMWR Morb Mortal Wkly Rep. 2009;58(44):1227-1232.

31. Goldberg ME, Liefeld J, Madill J, Vredenburg H. The effect of plain packaging on response to health warnings. Am J Public Health. 1999;89(9):1434-1435.

32. Beede P, Lawson R. The effect of plain packages on the perception of cigarette health warnings. Public Health. 1992;106(4):315-322.

33. Maynard OM, Munafò MR, Leonards U. Visual attention to health warnings on plain tobacco packaging in adolescent smokers and non-smokers. Addiction. 2013;108(2):413-419.

34. Munafò MR, Roberts N, Bauld L, Leonards U. Plain packaging increases visual attention to health warnings on cigarette packs in non-smokers and weekly smokers but not daily smokers. Addiction. 2011;106(8): $1505-1510$.

35. Moodie C, Mackintosh AM, Hastings G, Ford A. Young adult smokers' perceptions of plain packaging: a pilot naturalistic study. Tob Control. 2011;20(5):367-373.

36. Moodie CS, Mackintosh AM. Young adult women smokers' response to using plain cigarette packaging: a naturalistic approach. BMJ Open. 2013;3(3).

37. Arora M, Tewari A, Grills N, et al. Exploring perception of Indians about plain packaging of tobacco products: a mixed method research. Front Public Health. 2013;1:35.

38. Fix BV, O’Connor RJ, Fong GT, Borland R, Cummings KM, Hyland A. Smokers' reactions to FDA regulation of tobacco products: findings from the 2009 ITC United States survey. BMC Public Health. 2011;11:941.

39. Wakefield MA, Hayes L, Durkin S, Borland R. Introduction effects of the Australian plain packaging policy on adult smokers: a cross-sectional study. BMJ Open. 2013;3(7).

40. Hoek J, Wong C, Gendall P, Louviere J, Cong K. Effects of dissuasive packaging on young adult smokers. Tob Control. 2011;20(3): 183-188. 
41. Young JM, Stacey I, Dobbins TA, Dunlop S, Dessaix AL, Currow DC. Association between tobacco plain packaging and Quitline calls: a population-based, interrupted time-series analysis. Med J Aust. 2014;200(1):29-32.

42. Zacher M, Bayly M, Brennan E, et al. Personal tobacco pack display before and after the introduction of plain packaging with larger pictorial health warnings in Australia: an observational study of outdoor cafe strips. Addiction. 2014;109(4):653-662.

43. McClure SM, Li J, Tomlin D, Cypert KS, Montague LM, Montague PR. Neural correlates of behavioral preference for culturally familiar drinks. Neuron. 2004;44(2):379-387.

44. Schaefer M, Berens H, Heinze HJ, Rotte M. Neural correlates of culturally familiar brands of car manufacturers. Neuroimage. 2006;31(2):861-865.

45. Schaefer M, Rotte M. Combining a semantic differential with fMRI to investigate brands as cultural symbols. Soc Cogn Affect Neurosci. 2010;5(2-3):274-281.

46. Morris JD, Klahr NJ, Shen F, et al. Mapping a multidimensional emotion in response to television commercials. Hum Brain Mapp. 2009;30(3):789-796.

47. Bruce AS, Bruce JM, Black WR, et al. Branding and a child's brain: an fMRI study of neural responses to logos. Soc Cogn Affect Neurosci. 2014;9(1):118-122.

48. Bruce AS, Lepping RJ, Bruce JM, et al. Brain responses to food logos in obese and healthy weight children. J Pediatr. 2013;162(4): 759-764. e2

49. Lee JH, Lim Y, Wiederhold BK, Graham SJ. A functional magnetic resonance imaging (fMRI) study of cue-induced smoking craving in virtual environments. Appl Psychophysiol Biofeedback. 2005;30(3):195-204.

50. Wilson SJ, Sayett MA, Delgado MR, Fiez JA. Instructed smoking expectancy modulates cue-elicited neural activity: a preliminary study. Nicotine Tob Res. 2005;7(4):637-645.

51. Due DL, Huettel SA, Hall WG, Rubin DC. Activation in mesolimbic and visuospatial neural circuits elicited by smoking cues: evidence from functional magnetic resonance imaging. Am J Psychiatry. 2002;159(6): 954-960.

52. David SP, Munafò MR, Johansen-Berg H, et al. Ventral striatum/nucleus accumbens activation to smoking-related pictorial cues in smokers and nonsmokers: a functional magnetic resonance imaging study. Biol Psychiatry. 2005;58(6):488-494.

53. McClernon FJ, Hiott FB, Huettel SA, Rose JE. Abstinence-induced changes in self-report craving correlate with event-related fMRI responses to smoking cues. Neuropsychopharmacol. 2005;30(30):1940-1947.

54. Engelmann JM, Versace F, Robinson JD, et al. Neural substrates of smoking cue reactivity: a meta-analysis of fMRI studies. Neuroimage. 2012;60(1):252-262.

55. McBride D, Barrett SP, Kelly JT, Aw A, Dagher A. Effects of expectancy and abstinence on the neural response to smoking cues in cigarette smokers: an fMRI study. Neuropsychopharmacology. 2006;31(12):2728-2738.

56. Wilson SJ, Sayette MA, Fiez JA. Quitting-unmotivated and quittingmotivated cigarette smokers exhibit different patterns of cue-elicited brain activation when anticipating an opportunity to smoke. J Abnorm Psychol. 2012;121(1):198-211.
57. Goudriaan AE, Veltman DJ, van den Brink W, Dom G, Schmaal L. Neurophysiological effects of modafinil on cue-exposure in cocaine dependence: a randomized placebo-controlled cross-over study using pharmacological fMRI. Addict Behav. 2013;38(2): 1509-1517.

58. McClernon FJ, Kozink RV, Rose JE. Individual differences in nicotine dependence, withdrawal symptoms, and sex predict transient fMRI-BOLD responses to smoking cues. Neuropsychopharmacology. 2008;33(9):2148-2157.

59. Smolka M, Buhler M, Klein S, et al. Severity of nicotine dependence modulates cue-induced brain activity in regions involved in motor preparation and imagery. Psychopharmacology (Berl). 2006;184(3-4): 577-588.

60. Wilson SJ, Creswell KG, Sayette MA, Fiez JA. Ambivalence about smoking and cue-elicited neural activity in quitting-motivated smokers faced with an opportunity to smoke. Addict Behav. 2013;38(2): $1541-1549$.

61. Janes AC, Pizzagalli DA, Richardt S, et al. Brain reactivity to smoking cues prior to smoking cessation predicts ability to maintain tobacco abstinence. Biol Psychiatry. 2010;67(8):722-729.

62. Culbertson CS, Bramen J, Cohen MS, et al. Effect of bupropion treatment on brain activation induced by cigarette-related cues in smokers. Arch Gen Psychiatry. 2011;68(5):505-515.

63. Franklin T, Wang Z, Suh JJ, et al. Effects of varenicline on smoking cue-triggered neural and craving responses. Arch Gen Psychiatry. 2011;68(5):516-526.

64. Brody AL, Mandelkern MA, Lee G, et al. Attenuation of cue-induced cigarette craving and anterior cingulate cortex activation in bupropiontreated smokers: a preliminary study. Psychiatry Res. 2004;130(3): 269-281.

65. Falk EB, Berkman ET, Whalen D, Lieberman MD. Neural activity during health messaging predicts reductions in smoking above and beyond self-report. Health Psychol. 2011;30(2):177-185.

66. Falk EB, Berkman ET, Mann T, Harrison B, Lieberman MD. Predicting persuasion-induced behavior change from the brain. J Neurosci. 2010;30(25):8421-8424.

67. Falk EB, Rameson L, Berkman ET, et al. The neural correlates of persuasion: a common network across cultures and media. J Cogn Neurosci. 2010;22(11):2447-2459.

68. Wang AL, Romer D, Elman I, Turetsky BI, Gur RC, Langleben DD. Emotional graphic cigarette warning labels reduce the electrophysiological brain response to smoking cues. Addict Biol. Epub December 15, 2013.

69. Anderson NB. Levels of analysis in health science. A framework for integrating sociobehavioral and biomedical research. Ann NY Acad Sci. 1998;840:563-576.

70. Hiatt RA, Rimer BK. A new strategy for cancer control research. Cancer Epidemiol Biomarkers Prev. 1999;8(11):957-964.

71. Volkow N, Fowler J, Wang G. The addicted human brain: insights from imaging studies. J Clin Invest. 2003;111(10):1444-1451.

72. Baler RD, Volkow ND. Drug addiction: the neurobiology of disrupted self-control. Trends Mol Med. 2006;12(12):559-566.

Neuroscience and Neuroeconomics

\section{Publish your work in this journal}

Neuroscience and Neuroeconomics is an international, peer-reviewed, open access journal focusing on the identification of brain structures and measurement of neural activity related to behavior, behavioral predictions, and decision making in health and disease. The manuscript management system is completely online and includes a very quick and

php to read real quotes from published authors.

\section{Dovepress}

Submit your manuscript here: http://www.dovepress.com/neuroscience-and-neuroeconomics-journal 